\title{
COMPARISON OF MODIFIED DISCRIMINANT FUNCTION AND GLASGOW ALCOHOLIC HEPATITIS SCORE IN PREDICTING ONE MONTH MORTALITY
}

\author{
G. Vasumathi' ${ }^{1}$ S. Geetha ${ }^{2}$, G. Rengaraj ${ }^{3}$ \\ ${ }^{1}$ Associate Professor, Department of Medicine, Government Stanley Medical College, Chennai. \\ ${ }^{2}$ Assistant Professor, Department of Medicine, Government Stanley Medical College, Chennai. \\ ${ }^{3}$ Senior Resident, Department of Medicine, Government Stanley Medical College, Chennai.
}

\begin{abstract}
\section{BACKGROUND}

Alcoholic Liver Disease (ALD) includes a wide range of injury from reversible steatosis, steatohepatitis to irreversible cirrhosis. Alcoholic hepatitis is a very important entity, because severe alcoholic hepatitis is associated with a high short term mortality rate of $40-45 \%$, which is unacceptable and has to be prevented. So far the severity of alcoholic hepatitis is identified by calculating 'Modified Discriminant Function' (mDF) score. This score includes only Prothrombin Time (PT) and bilirubin in calculating the severity of alcoholic hepatitis. MDF of greater than or equal to 32 is considered severe and treated with steroids and pentoxifylline. New scoring system 'Glasgow Alcoholic Hepatitis Score (GAHS) which includes age, white cell count, urea, PT and serum bilirubin level is used in identifying the patients in need of drug therapy.
\end{abstract}

\section{AIM OF THE STUDY}

To compare GAHS score with mDF score to predict one month mortality in alcoholic hepatitis patients.

\section{METHODS}

Prospective observational study of 50 patients of Alcoholic Hepatitis patients in the Departments of General Medicine and Medical Gastroenterology of Stanley Medical College, Chennai, was done in the year March 2012 to August 2012.

\section{RESULTS}

The results show GAHS score is found to have higher sensitivity, specificity, positive predictive value, negative predictive value and diagnostic accuracy when compared to mDF score.

\section{KEYWORDS}

Alcoholic Hepatitis, mDF Score, GAHS Score.

HOW TO CITE THIS ARTICLE: G. Vasumathi, S. Geetha, G. Rengaraj. "Comparison of Modified Discriminant Function and Glasgow Alcoholic Hepatitis Score in Predicting One Month Mortality." Journal of Evolution of Medical and Dental Sciences 2015; Vol. 4, Issue 97, December 03; Page: 16236-16241, DOI: 10.14260/jemds/2015/2391

\section{INTRODUCTION}

Liver is the major organ of alcohol metabolism. Alcohol is metabolized by 3 major enzyme systems.

1. Alcohol Dehydrogenase-ADH (80\% to $85 \%)$.

2. Cytochrome P450 isoenzyme namely Cytochrome P4502E1(10\% to $15 \%)$.

3. Catalase (less than $5 \%$ ).

The above enzyme systems convert alcohol to acetaldehyde, which is a highly reactive and toxic compound. Acetaldehyde forms adducts with proteins, which induce host's immune system and results in autoimmune-like mechanisms. Oxidative stress-CYP2E1 leaks electrons to initiate Oxidative Stress in Hepatocytes. Alcohol increases intestinal permeability causing frequent endotoxemia, which in turn increases production of TNF alpha by Kupffer cells. TNF alpha activates chemokines (IL-8), which leads to

Financial or Other, Competing Interest: None.

Submission 10-11-2015, Peer Review 11-11-2015,

Acceptance 26-11-2015, Published 02-12-2015.

Corresponding Author:

Dr. G. Vasumathi,

52, Madipakkam Main Road,

Madipakkam,

Chennai-91.

E-mail: vasumathivenkatesan@yahoo.co.in

DOI:10.14260/jemds/2015/2391 inflammation, fibrosis apoptosis and organ damage. Alcoholic hepatitis is a clinical syndrome of icterus and hepatic dysfunction that usually manifest following continuous excessive alcohol intake (an average of 100grams/day). The usual age at which the disease presents is 40 to 60 years, but can vary from 20 to 80 years. The cardinal sign is rapid onset of jaundice. Typically, the liver is enlarged and tender. ${ }^{1}$ The importance of alcoholic hepatitis lies in its potential reversibility.

\section{Histological Characteristics of Alcoholic Hepatitis}

1. Ballooning of hepatocytes,

2. Mallory bodies - eosinophilic cytoplasmic inclusions,

3. Neutrophilic infiltration surrounding the degenerating hepatocyte.

\section{Diagnosis of Alcohol Abuse}

The diagnosis of alcohol abuse can be done by using AUDIT. ${ }^{2}$ (Alcohol Use Disorders Identification Test) or CAGE. ${ }^{2}$ questionnaire, of which we used AUDIT. It is a 10 -item questionnaire designed by the WHO for screening of problem drinking. A total $\geq 8$ for men up to age 60 or $\geq 7$ for women, adolescents, or men over 60 is considered positive screening test. Any value greater than this is suggestive of alcohol abuse. 


\section{Diagnosis of Alcoholic Hepatitis}

The disease is suspected when icterus and other symptoms and signs of decompensation like ascitis happens to an individual with excess ethanol intake.(3) Clinical diagnosis has an accuracy of about $80 \%$ when compared with histology. However, along with history of chronic excess alcohol ingestion, AST $>500$ (or ALT<300). Serum bilirubin was set at a minimum level of $>80 \mu \mathrm{mol} / \mathrm{L}(4.67 \mathrm{mg} / \mathrm{dl})$, the accuracy becomes $99.2 \%$. In this study too the inclusion criteria of serum bilirubin is $>5 \mathrm{mg} / \mathrm{dl}$. To improve the diagnostic accuracy measurement of prothrombin time in patients has high prognostic value. An abnormal prothrombin time with confirmed PT $>5$ to 6 seconds above control often precedes by days the manifestations of liver failure. The degree of prolongation of PT is a prognostic factor for patients with alcoholic steatonecrosis. Progressive return of PT to normal accompanies other evidence of clinical improvement.

\section{Complete Blood Count:}

Mild anemia (usually macrocytic), platelets in the range of normal to decreased and elevated white cell count. $\mathrm{PMN}>5500$ in the presence of $\mathrm{mDF}>32$ indicates poor prognosis. Values of urea and creatinine rises. These elevations are found to have significant correlation with the severity of the disease Percutaneous liver biopsy cannot be performed in patients with ascitis and/or coagulopathy and transjugular biopsy needs expertise.

\section{SCORING SYSTEM}

Discriminant Function $=(4.6 x \mathrm{PT})+\operatorname{serum}$ bilirubin $(\mathrm{mg} / \mathrm{dl}) 1$. mDF Modified Discriminant Function.

It is discovered by Maddrey and Boitnott. It is calculated as $4.6 \times \mathrm{PT}$ prolongation [patient's-control value (seconds)]+serum bilirubin(mg/dl). The $\mathrm{mDF}$ is proved useful for delineating 28 days and 84 days mortality. Evidence has proven that patients with an mDF value of 32 or more experienced a worse prognosis with 28 days mortality rates of $35 \%$ to $45 \%$.

In contrast patients with an mDF value less than 32 have short survival rates of $90 \%$ to $100 \%$. MELD Score $=3.78$ [serum bilirubin $(\mathrm{mg} / \mathrm{dl})]+11.2 \quad[\mathrm{INR}]+9.57 \quad$ [serum creatinine $(\mathrm{mg} / \mathrm{dl})]+6.43$ includes the serum bilirubin level, INR along with creatinine level. Prognosis is poor if the score is $\geq 18$.

The disadvantage in MELD score is that it needs calculators for calculation since it involves logarithms. It includes creatinine as a measure of renal function. Evaluation of creatinine is commonly done based on Jaffe reaction. In diseases associated with hyperbilirubinemia, creatinine will be underestimated. So the observed value based on Jaffe's method needs correction, which is cumbersome.

Glasgow alcoholic hepatitis score includes age, WBC count, urea level, serum bilirubin level, prothrombin time ratio; i.e., ratio of the patient's prothrombin time to the control value also have been shown to predict survival in patients with severe alcoholic hepatitis. Because both the MELD and Glasgow scores include measures of renal functions, they appear to be more accurate than the $\mathrm{mDF}$ in determining the prognosis of patients.

\begin{tabular}{|c|c|c|c|}
\hline Score & 1 & 2 & 3 \\
\hline Age & $<50$ & $>50$ & \\
\hline WCC $\left(10^{9}\right)$ & $<15$ & $>15$ & \\
\hline Urea $(\mathrm{mmol} / \mathrm{L})$ & $<5$ & $>5$ & \\
\hline PT ratio or INR & $<1.5$ & $1.5-2$ & $>2$ \\
\hline Bilirubin $(\mu \mathrm{mol} / \mathrm{l})$ & $<125$ & $125-250$ & $>250$ \\
\hline
\end{tabular}

Table 1: Glasgow Alcoholic Hepatitis Score

GAHS is more easy to calculate and it uses urea as a measure of renal function. Prognosis is poor if the score is $\geq 9$.

\section{MATERIALS AND METHODS}

Study Design : Observational study.

Study Place : Departments of General Medicine and Medical Gastroenterology, Government Stanley Medical Hospital, Chennai-1.

Study Period : 6 months (March 2012-August 2012).

Study

Population : Patients admitted with alcoholic hepatitis.

Sample Size : 50 patients.

Sampling : Simple Random Sampling.

\section{How this Study was Conducted}

Patients admitted with alcoholic hepatitis were included in the study after applying the inclusion and exclusion criteria. They were subjected to thorough history, clinical examination, biochemical investigations, ultrasonogram of the abdomen. They were followed up after one month of their present admission.

\section{Assessment Panel Includes}

History with specific focus on alcoholic intake-amount, type and duration and with AUDIT score $\geq 8$ in males and $\geq 7$ in females and elderly males' age.

\section{Biochemical Investigations}

White cell count, serum urea, serum albumin, PT and INR, SGOT and SGPT, ultrasonogram of abdomen done to exclude cirrhosis and malignancy. Results were duely collected and analysed. The patients were followed up for one month and the mortality is assessed. MDF and GAHS were calculated.

The patients with $\mathrm{mDF} \geq 32$ or GAHS score $\geq 9$ were given prednisolone for 4 weeks and then tapered over next 4 weeks. If the patient had contra indications to steroids, Pentoxyphyllin is given. The patients were followed for one month and the mortality is observed. Sensitivity, specificity and accuracy of mDF and GAHS in calculating one mortality were calculated. The results were analysed. P-value of 0.05 is considered statistically significant.

\section{RESULTS}

This study included 50 patients diagnosed with alcoholic hepatitis admitted in Department of General Medicine and Medical Gastroenterology, Government Stanley Hospital. The one month mortality prediction by modified discriminant function and GAHS score is calculated and compared with observed one month mortality. The results were tabulated and analysed as follows:

\begin{tabular}{|c|c|c|}
\hline AGE GROUP [Years] & Number & Percentage \\
\hline $21-30$ & 7 & 14 \\
\hline $31-40$ & 18 & 36 \\
\hline $41-50$ & 16 & 32 \\
\hline Above 51 & 9 & 18 \\
\hline \multicolumn{2}{|c}{ Table 2: Age Distribution } \\
\hline
\end{tabular}




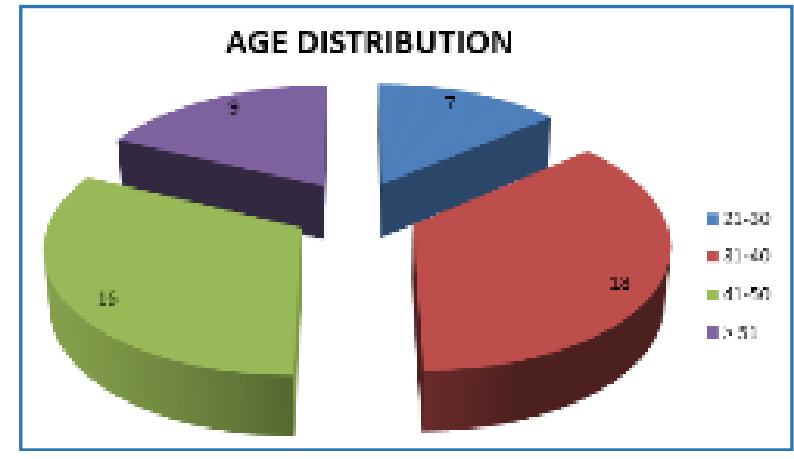

Fig. 1

\begin{tabular}{|c|c|c|c|c|c|c|c|}
\hline \multirow{2}{*}{$\begin{array}{c}\text { Age } \\
\text { Group } \\
\text { (Years) }\end{array}$} & \multicolumn{3}{|c|}{$\mathbf{1}$ Month Mortality } & \multicolumn{2}{|c|}{ Total } & \multirow{2}{*}{$\begin{array}{c}\text { P- } \\
\text { Value }\end{array}$} \\
\cline { 2 - 7 } & Survived & \multicolumn{2}{|c|}{ Died } & \multicolumn{2}{|c|}{} \\
\hline $21-30$ & 7 & $\mathbf{\%}$ & $\mathbf{N}$ & $\mathbf{\%}$ & $\mathbf{N}$ & $\mathbf{\%}$ & \\
\hline $31-40$ & 14 & 77.8 & 4 & 22.2 & 18 & 100.0 & \\
\hline $41-50$ & 11 & 68.8 & 5 & 31.3 & 16 & 100.0 & \multirow{2}{*}{0.005} \\
\hline$>51$ & 3 & 33.3 & 6 & 66.7 & 9 & 100.0 & \\
\hline Total & $\mathbf{3 5}$ & $\mathbf{7 0 . 0}$ & $\mathbf{1 5}$ & $\mathbf{3 0 . 0}$ & $\mathbf{5 0}$ & $\mathbf{1 0 0 . 0}$ & \\
\hline
\end{tabular}

This table shows that as age increases the mortality increases too.

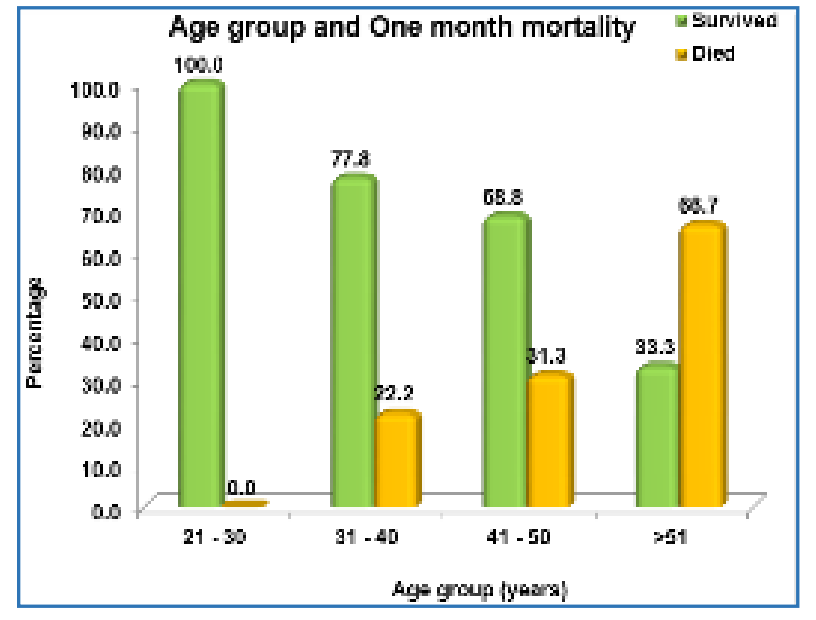

Fig. 2

AGE

\begin{tabular}{|c|c|c|c|c|c|}
\hline Variable & $\begin{array}{c}\text { 1 Month } \\
\text { Mortality }\end{array}$ & N & Mean & $\begin{array}{c}\text { Std. } \\
\text { Deviation }\end{array}$ & $\begin{array}{c}\text { P- } \\
\text { Value }\end{array}$ \\
\hline $\begin{array}{c}\text { Age } \\
\text { (Years) }\end{array}$ & Survived & 35 & 38.23 & 7.99 & \multirow{2}{*}{0.002} \\
\cline { 2 - 5 } & Died & 15 & 46.80 & 9.33 & \\
\hline
\end{tabular}

Table 4: Independent Samples T-Test to Compare Mean Values between Variables

This table shows that patients who survived had a mean age of 38.23, whereas patients who died at the end of 1 month had a mean age of 46.8. This difference is significant as suggested by a P-value of 0.002 .

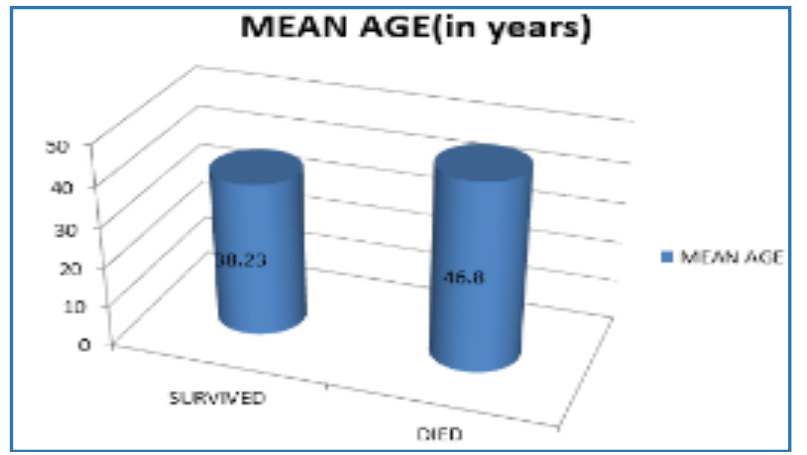

Fig. 3

\begin{tabular}{|c|c|c|c|c|c|}
\hline Variable & $\begin{array}{c}\text { 1 Month } \\
\text { Mortality }\end{array}$ & $\mathbf{N}$ & Mean & $\begin{array}{c}\text { Std. } \\
\text { Deviation }\end{array}$ & $\begin{array}{c}\text { P- } \\
\text { Value }\end{array}$ \\
\hline \multirow{2}{*}{ WCC } & Survived & 35 & 8917.1 & 3324.5 & \multirow{2}{*}{$<0.001$} \\
\cline { 2 - 5 } & Died & 15 & 15913.3 & 4652.6 & \\
\hline \multicolumn{6}{|c|}{ Table 5: White Cell Count } \\
\hline
\end{tabular}

Patients who died at the end of 1 month had significantly raised white cell count (mean of 15913) with a P-value of $<0.001$ indicating the importance of white cell count in indicating the prognosis of alcoholic hepatitis.

\begin{tabular}{|c|c|c|c|c|c|}
\hline Variable & $\begin{array}{c}\text { 1 Month } \\
\text { Mortality }\end{array}$ & N & Mean & $\begin{array}{c}\text { Std. } \\
\text { Deviation }\end{array}$ & $\begin{array}{c}\text { P- } \\
\text { Value }\end{array}$ \\
\hline \multirow{2}{*}{ Urea } & Survived & 35 & 31.74 & 8.98 & \multirow{2}{*}{0.014} \\
\cline { 2 - 5 } & Died & 15 & 38.63 & 8.15 & \\
\hline \multicolumn{6}{|c|}{ Table 6: Serum Urea } \\
\hline
\end{tabular}

Patients who died at the end of 1 month had significant rise in urea compared to those survived (p-0.014), indicating renal involvement altering the prognosis of alcoholic hepatitis.

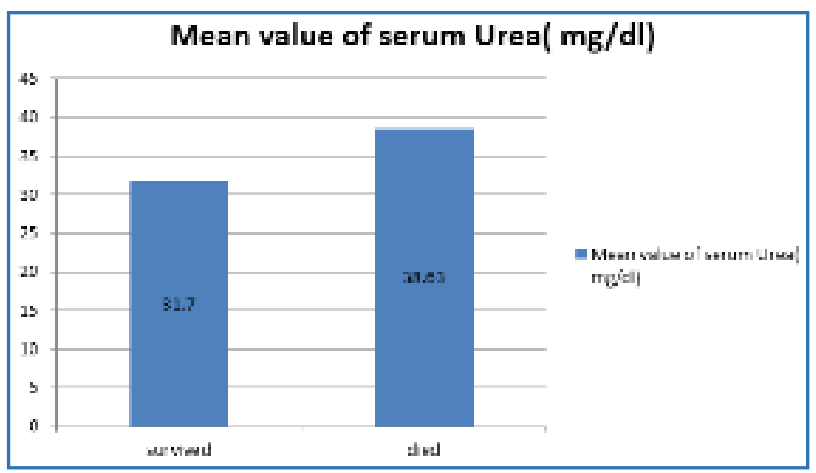

Fig. 4

\begin{tabular}{|c|c|c|c|c|c|}
\hline Variable & $\begin{array}{c}\text { 1 Month } \\
\text { Mortality }\end{array}$ & N & Mean & $\begin{array}{c}\text { Std. } \\
\text { Deviation }\end{array}$ & $\begin{array}{c}\text { P- } \\
\text { Value }\end{array}$ \\
\hline $\begin{array}{c}\text { Total } \\
\text { Bilirubin }\end{array}$ & Survived & 35 & 8.81 & 2.46 & \multirow{2}{*}{0.007} \\
\cline { 2 - 5 } & Died & 15 & 13.39 & 5.57 & \\
\hline \multicolumn{7}{c}{ Table 7: Serum Bilirubin } \\
\hline
\end{tabular}

The average value of serum bilirubin in patients who died was 13.3, compared the value of 8.81 in those who survived ( $p$ - value $=0.007$ ) indicating its value in assessing the prognosis. 


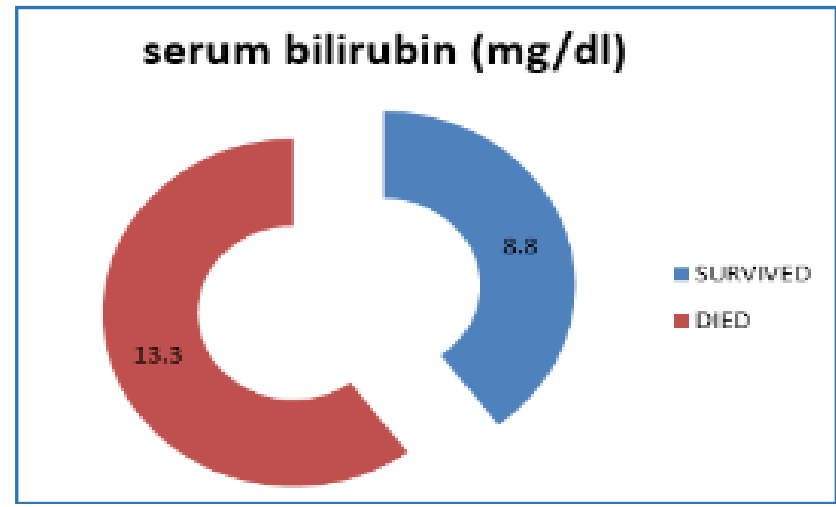

Fig. 5

\begin{tabular}{|c|c|c|c|c|c|}
\hline Variable & $\begin{array}{c}\text { 1 Month } \\
\text { Mortality }\end{array}$ & N & Mean & $\begin{array}{c}\text { Std. } \\
\text { Deviation }\end{array}$ & $\begin{array}{c}\text { P- } \\
\text { Value }\end{array}$ \\
\hline \multirow{2}{*}{ PT } & Survived & 35 & 17.17 & 2.07 & \multirow{2}{*}{0.073} \\
\cline { 2 - 5 } & Died & 15 & 18.33 & 2.02 & \\
\hline \multicolumn{6}{|c}{ Table 8: Prothrombin Time } \\
\end{tabular}

In our study, the prothrombin time among the patients who died was raised compared to those who survived, but this rise was not statistically significant (P-value-0.073).

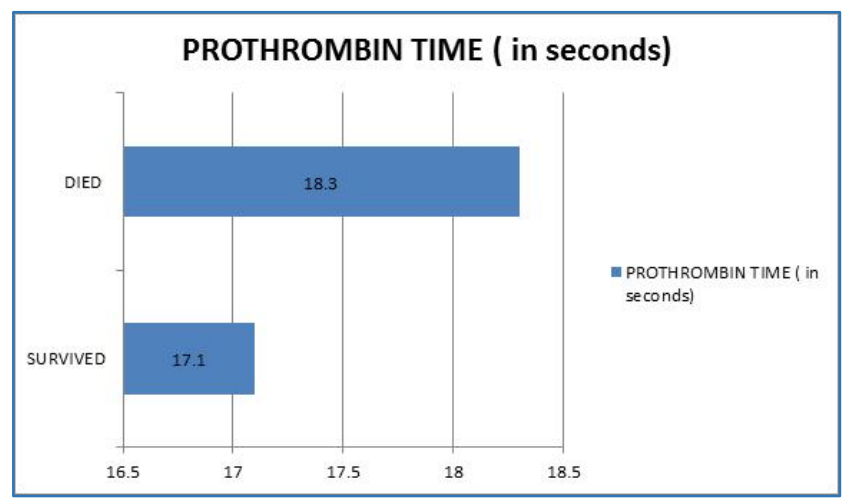

Fig. 6

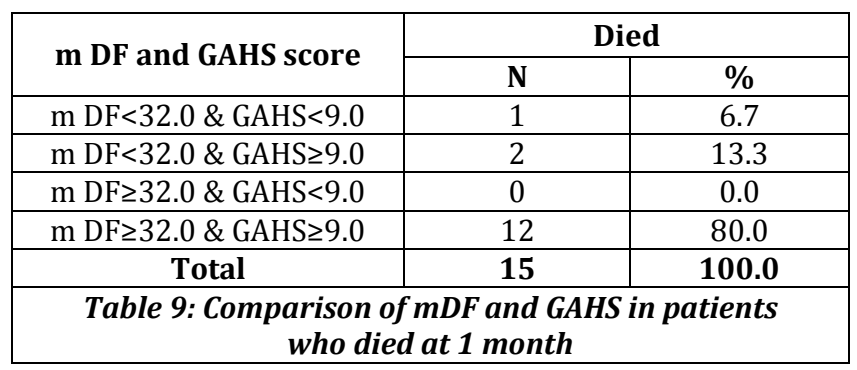

Of the 15 patients who died, 12 were detected as having severe disease by both $\mathrm{mDF}$ and GAHS. But 2 patients who had $\mathrm{mDF}<32$ and GAHS $\geq 9$ died. These patients if identified as severe could have benefitted with steroids or pentoxifylline. One patient who had both $\mathrm{mDF}<32$ and GAHS $<9$ died and both scores failed to identify the severity. GAHS identifies severity in all patients identified by $\mathrm{mDF} \geq 32$, apart from identifying severe disease in patients with $\mathrm{mDF}<32$. The only patient where GAHS failed, mDF too failed to identify the severity.

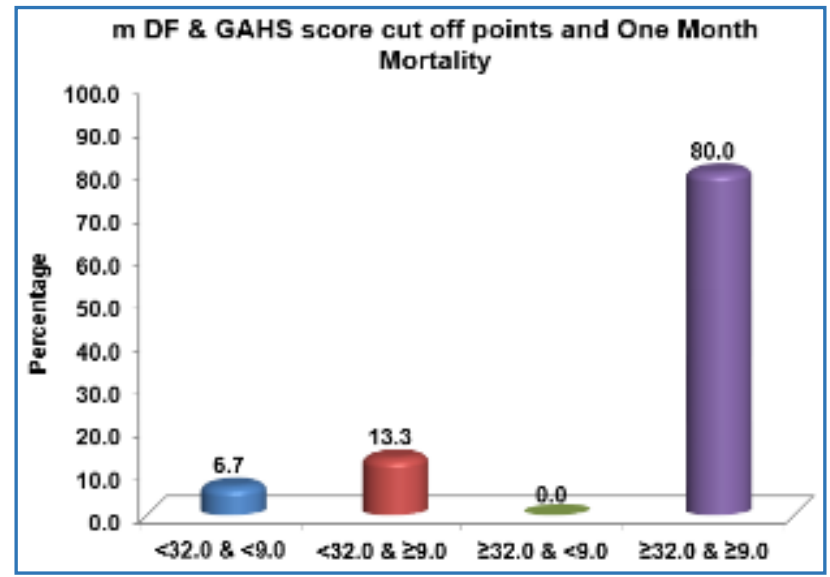

Fig. 7

Kappa Statistics to measure the Agreement between the Two Scoring Procedures

\begin{tabular}{|l|c|c|c|c|}
\hline \multicolumn{2}{|c|}{} & \multicolumn{2}{c|}{ mDF Score } & \multirow{2}{*}{ Total } \\
\cline { 3 - 4 } \multicolumn{2}{|c|}{} & $\geq \mathbf{3 2 . 0}$ & $<\mathbf{3 2 . 0}$ & \\
\hline \multirow{2}{*}{$\begin{array}{l}\text { GAHS } \\
\text { Score }\end{array}$} & $\geq 9$ & 14 & 2 & 16 \\
\cline { 2 - 4 } & $<9$ & 9 & 25 & 34 \\
\hline \multicolumn{2}{|c|}{ Total } & $\mathbf{2 3}$ & $\mathbf{2 7}$ & $\mathbf{5 0}$ \\
\hline \multicolumn{3}{|c|}{ Table 10 } \\
\hline
\end{tabular}

\begin{tabular}{|c|c|c|}
\hline Measure of Agreement & Value & P-Value \\
\hline Kappa & 0.547 & $<0.001$ \\
\hline \multicolumn{3}{|c|}{ Table 11 } \\
\hline
\end{tabular}

Kappa value of 0.547 shows only moderate agreement between GAHS and $\mathrm{mDF}$.

ROC Curve analysis to find out the best cut-off point for GAHS to predict the 1 month mortality.

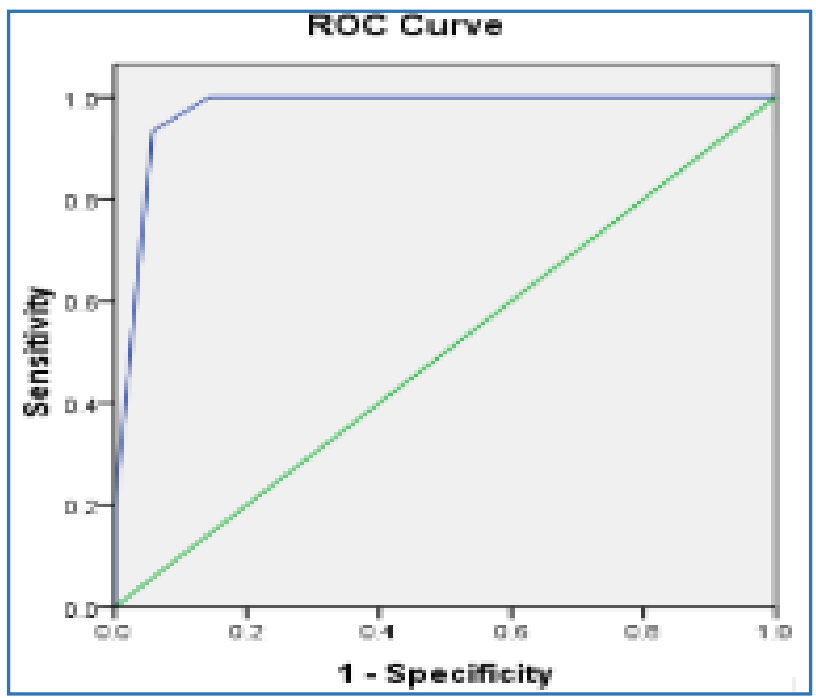

Fig. 8

Area Under the Curve $\mathbf{= 0 . 9 7 2}$

The ROC curve analysis suggests that GAHS value $\geq 9.0$ is the best cut-off point to predict the 1 month mortality. 
Sensitivity Specificity Analysis for mDF

\begin{tabular}{|c|c|c|c|c|}
\hline & \multicolumn{2}{|c|}{1 Month Mortality } & \multirow{2}{*}{ Total } \\
\hline & & Died & Survived & \\
\hline \multirow{2}{*}{$\begin{array}{l}\text { mDF } \\
\text { Score }\end{array}$} & $\geq 32$ & 13 & 12 & 25 \\
\hline & $<32$ & 2 & 23 & 25 \\
\hline \multicolumn{2}{|c|}{ Total } & 15 & 35 & 50 \\
\hline \multicolumn{5}{|c|}{ Table 12} \\
\hline
\end{tabular}

\begin{tabular}{|c|c|c|}
\hline Parameter & $\begin{array}{c}\text { Estimate } \\
\text { (\%) }\end{array}$ & $\begin{array}{c}\text { Lower- } \\
\text { Upper } \\
\text { 95\% CIs }\end{array}$ \\
\hline Sensitivity & 86.67 & $62.12,96.26$ \\
\hline Specificity & 65.71 & $49.15,79.17$ \\
\hline Positive Predictive Value & 52.00 & $33.50,69.97$ \\
\hline Negative Predictive Value & 92.00 & $75.03,97.78$ \\
\hline Diagnostic Accuracy & 72.00 & $58.33,82.53$ \\
\hline \multicolumn{2}{|c|}{ Table 13 }
\end{tabular}

Thus mDF has an accuracy of $72 \%$ in predicting 1 month mortality. Also, out of 25 patients who had discriminant function of $>32,13$ patients died and 12 survived with a specificity of $65.7 \%$. Out of 25 patients who had score $<32,2$ patients died. Also, the positive predictive value is low (52\%).

\section{Sensitivity Specificity Analysis for GAHS}

\begin{tabular}{|c|c|c|c|c|}
\hline & \multicolumn{2}{|c|}{1 Month Mortality } & \multirow[t]{2}{*}{ Total } \\
\hline & & Died & Survived & \\
\hline \multirow[t]{2}{*}{ GAHS Score } & $\geq 9$ & 14 & 2 & 16 \\
\hline & $<9$ & 1 & 33 & 34 \\
\hline \multicolumn{2}{|c|}{ Total } & 15 & 35 & 50 \\
\hline \multicolumn{5}{|c|}{ Table 14} \\
\hline
\end{tabular}

\begin{tabular}{|c|c|c|}
\hline Parameter & $\begin{array}{c}\text { Estimate } \\
\text { (\%) }\end{array}$ & $\begin{array}{c}\text { Lower-Upper } \\
\text { 95\% CIs }\end{array}$ \\
\hline Sensitivity & 93.33 & $70.18,98.81$ \\
\hline Specificity & 94.29 & $81.39,98.42$ \\
\hline Positive Predictive Value & 87.50 & $63.98,96.50$ \\
\hline Negative Predictive Value & 97.06 & $85.08,99.48$ \\
\hline Diagnostic Accuracy & 94.00 & $83.78,97.94$ \\
\hline \multicolumn{2}{|c|}{ Table 15 }
\end{tabular}

Thus GAHS has higher sensitivity, specificity, positive predictive value, negative predictive value and diagnostic accuracy when compared to mDF. Among these the specificity, positive predictive value and accuracy of GAHS is significantly higher compared to mDF. Hence, GAHS identifies the severity of alcoholic hepatitis accurately compared to $\mathrm{mDF}$ and this should be used in deciding upon treatment with steroids or pentoxifylline.

\begin{tabular}{|c|c|c|}
\hline Parameter & mDF & GAHS \\
\hline Sensitivity & 86.67 & 93.33 \\
\hline Specificity & 65.71 & 94.29 \\
\hline Positive Predictive Value & 52.00 & 87.50 \\
\hline Negative Predictive Value & 92.00 & 97.06 \\
\hline Diagnostic Accuracy & 72.00 & 94.00 \\
\hline \multicolumn{3}{|c|}{ Table 16 } \\
\hline
\end{tabular}

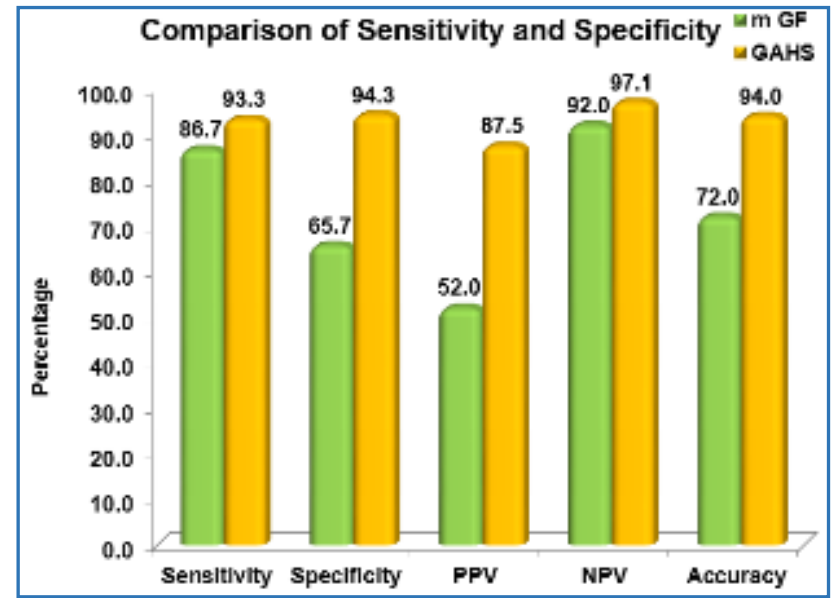

Fig. 9

\section{DISCUSSION}

Alcoholic hepatitis when severe, the short term mortality is very high. This high mortality is mainly due to inflammatory processes occurring in acute alcoholic hepatitis. Identification of patients with severe disease is of key significance, because these patients can be treated with steroids or pentoxifylline and these patients need to be monitored for the development of complications like hepatic encephalopathy and renal failure.

Also these patients need to be followed up periodically because alcoholic hepatitis in the long run is associated with nine times increased risk of development of cirrhosis. The severity of disease is identified by $\mathrm{mDF}$ score $\geq 32$. But the problem with this score is that it involves only serum bilirubin and prothrombin time.

It does not include any markers for inflammation or renal involvement. The MELD score is cumbersome to calculate and it too does not involve any marker for inflammation. The GAHS is easy to calculate, involves markers for renal involvement and inflammation and is much more accurate than mDF. Our study which was an observational study involved 50 patients with alcoholic hepatitis and comparison of actual prognosis with prognosis and severity calculated by $\mathrm{mDF}$ and GAHS. The observed mortality was $30 \%$.

The severity predicted by GAHS had an accuracy of $94 \%$ compared to that calculated by $\mathrm{mDF}$, which had $72 \%$ accuracy. Thus it is obvious that GAHS has much better severity prediction compared to $\mathrm{mDF}$ and this is helpful in treating patients. Also patients with GAHS $<9$ survived irrespective of their $\mathrm{mDF}$, even if $\mathrm{mDF} \geq 32$. This shows that if GAHS $<9$, these patients need not be treated with steroids or pentoxifylline. There are many studies reported in literature, comparing the various prognostic scoring systems. 


\begin{tabular}{|c|c|c|}
\hline 4 & $\begin{array}{c}\text { Population } \\
\text { (Number) }\end{array}$ & Results \\
\hline EH Forrest.(4) & 241 & $\begin{array}{c}\text { GAHS more accurate } \\
\text { than mDF in predicting } \\
\text { 28 and 84 day mortality }\end{array}$ \\
\hline $\begin{array}{c}\text { Altamirano- } \\
\text { Gomez }\end{array}$ & 120 & $\begin{array}{c}\text { GAHS superior to mDF } \\
\text { in predicting in-hospital } \\
\text { mortality }\end{array}$ \\
\hline Sandahl.(5) & 274 & $\begin{array}{c}\text { GAHS, MELD and ABIC } \\
\text { scores are equal in } \\
\text { accuracy }\end{array}$ \\
\hline H Lafferty & 182 & $\begin{array}{c}\text { Improvement in } \\
\text { outcome if patients are } \\
\text { treated with GAHS } \\
\text { grading for severity. }\end{array}$ \\
\hline AJ Morris & 225 & $\begin{array}{c}\text { At GAHS <9, no } \\
\text { significant benefits with } \\
\text { corticosteroids. } \geq 9 \text { has } \\
\text { poor prognosis if not } \\
\text { treated }\end{array}$ \\
\hline Palaniappan.(6) & 44 & $\begin{array}{c}\text { mDF, MELD,GAHS and } \\
\text { ABIC are equal in } \\
\text { accuracy. CP score is } \\
\text { poor in accuracy. }\end{array}$ \\
\hline S. Ali & 82 & $\begin{array}{c}\text { mDF, CP, GAHS are } \\
\text { equal in accuracy. }\end{array}$ \\
\hline \multicolumn{2}{|c|}{ Table 17 } \\
\hline
\end{tabular}

These studies show the accuracy of GAHS in comparison with other prognostic scoring systems.

\section{CONCLUSIONS}

1) The GAHS score (94\%) accurately predicted 1 month mortality when compared with $\mathrm{mDF}(72 \%)$.

2) The specificity and positive predictive value of GAHS (94.3\% and $87.5 \%)$ were far more superior compared to $\operatorname{mDF}(65.7 \%$ and $52 \%)$.
3) Out of the 25 patients with $\mathrm{mDF}<32$, three patients died. Of these three patients, two had GAHS $\geq 9$ indicating that had GAHS been used to identify the severity. These patients could have benefitted with treatment of corticosteroids or pentoxifylline.

4) One patient who died had both GAHS $<9$ and $\mathrm{mDF}<32$. In this case, both scores failed to identify the severity.

5) Each factor included in GAHS - Age, bilirubin, urea and white cell count with exception of prothrombin time had statistically significant rise in those patients who died compared to the survivors indicating that each factor itself gives a clue to the prognosis of the disease.

\section{BIBLIOGRAPHY}

1. Review article on clinical presentation of alcoholic hepatitis, Michael R Lucaey, MD, Philipe Mathurin, MD, $\mathrm{PhD}$, and Trimothy R Morgan MD, NEJM 2009;360:2758-69.

2. Harrison's "Principles of Internal Medicine" $18^{\text {th }}$ edition.; Vol.2; 2589-91.

3. A clinical approach to alcoholic hepatitis. Forrest EF, JR coll Physicians Edinb 2007;37:3-8.

4. GAHS score identifies patients who may benefit from corticosteroids, Forrest EH, GUT 2007;56:1743-46.

5. Validation of prognostic scores for clinical use in patients with alcoholic hepatitis. Sandahl, Scand J Gastro 2011 sep; 46(9):1127-32. doi:10.3109/00365521. 2001.587200. Epub 2011 May 18.

6. The utility of scoring systems in predicting early and late mortality in alcoholic hepatitis. Who score is it anyway Navneetham Palaniappan. International Journal of Hepatology 2012, Article ID 624675, 5 pages. doi:10.1155/2012/624675. 